\title{
A Lifestyle Physical Activity Intervention for Patients with Chronic Obstructive Pulmonary Disease
} A Randomized Controlled Trial

\author{
David B. Coultas ${ }^{1,2}$, Bradford E. Jackson ${ }^{3}$, Rennie Russo ${ }^{4}$, Jennifer Peoples ${ }^{4}$, John Sloan ${ }^{5}$, Karan P. Singh ${ }^{3}$, \\ Jamile Ashmore ${ }^{6}$, Steven N. Blair ${ }^{7}$, Minyong Uhm ${ }^{3}$, and Sejong $\mathrm{Bae}^{3}$
}

${ }^{1}$ Veterans Affairs Portland Health Care System, Portland, Oregon; ${ }^{2}$ Oregon Health Science University, Portland, Oregon; ${ }^{3}$ Division of Preventive Medicine, University of Alabama at Birmingham, Birmingham, Alabama; ${ }^{4}$ Department of Medicine, University of Texas Health Sciences Center at Tyler, Tyler, Texas; ${ }^{5}$ Department of Health and Kinesiology, University of Texas at Tyler, Tyler, Texas; ${ }^{6}$ Behavioral Health Center, Baylor Medical Center, Plano, Texas; and ${ }^{7}$ Arnold School of Public Health, University of South Carolina, Columbia, South Carolina

\begin{abstract}
Rationale: Physical inactivity is associated with poor outcomes among patients with chronic obstructive pulmonary disease (COPD).

Objectives: To determine effectiveness of a behavioral intervention intended to increase daily physical activity with the goal of improving health-related quality of life and functional performance.
\end{abstract}

Methods: We conducted a randomized trial among patients with COPD cared for in primary care and pulmonary clinics. The patients were at least 45 years of age and eligible for pulmonary rehabilitation. All patients received self-management education during a 6-week run-in period. Subsequently, patients were randomized to usual care or the intervention delivered over 20 weeks.

Measurements and Main Results: Co-primary outcomes were change from baseline in Chronic Respiratory Questionnaire dyspnea domain score and 6-minute-walk distance measured at 6, 12, and 18 months after randomization. A total of 325 patients were enrolled, with 156 randomized to receive usual care and 149 to receive the intervention. At 18 months, there was no overall statistical or clinically significant change in the dyspnea domain in either group. However, for 6-minute-walk distance, there were statistically significant declines in both groups. In contrast, 6-minute-walk distance remained stable $(5.3 \mathrm{~m} ; P=0.54)$ among patients in the intervention group with moderate spirometric impairment, but it was associated with clinically and statistically significant declines $(-28.7 \mathrm{~m} ; P=0.0001)$ among usual care patients with moderate spirometric impairment. Overall, there was no increase in adverse events associated with the intervention, which was associated with a lower prevalence of hospitalization for COPD exacerbations $(28.3 \%)$ compared with usual care (49.5\%).

Conclusions: During this 18-month trial among outpatients with COPD, a health coach-based behavioral intervention did not improve scores in the dyspnea domain of the Chronic Respiratory Questionnaire or 6-minute-walk test distance. However, subgroup analyses suggested that there may be differential effects for specific outcomes that vary with severity of COPD. Specifically, benefits of this low-intensity intervention may be limited to 6-minute walk distance among patients with moderate spirometric impairment.

Clinical trial registered with www.clinicaltrials.gov (NCT1108991).

Keywords: chronic obstructive pulmonary disease; physical activity; pulmonary rehabilitation; randomized trial; self-management

(Received in original form August 10, 2015; accepted in final form January 19, 2016)

Funded by National Heart, Lung, and Blood Institute grant R18 HL092955 from the National Institutes of Health. The contents of this paper do not represent the views of the Department of Veterans Affairs or the U.S. government.

Author Contributions: All authors approved the final version of the manuscript and attest to its accuracy. Study conception and design: D.B.C., K.P.S., J.A., S.N.B., and S.B.; data acquisition and management: D.B.C., B.E.J., R.R., J.P., J.S., K.P.S., J.A., M.U., and S.B.; data analysis and interpretation: D.B.C., B.E.J., K.P.S., J.A., S.N.B., M.U., and S.B.; drafting of the manuscript: D.B.C.; and critical revision of the manuscript: D.B.C., B.E.J., R.R., J.P., J.S., K.P.S., J.A., S.N.B., M.U., and S.B.

Correspondence and requests for reprints should be addressed to David B. Coultas, M.D., Veterans Affairs Portland Health Care System, 3710 S.W. U.S. Veterans Hospital Road, Portland, OR 97239. E-mail: david.coultas@va.gov

This article has an online supplement, which is accessible from this issue's table of contents at www.atsjournals.org

Ann Am Thorac Soc Vol 13, No 5, pp 617-626, May 2016

Copyright (C) 2016 by the American Thoracic Society

DOI: 10.1513/AnnalsATS.201508-5080C

Internet address: www.atsjournals.org 
Physical inactivity is associated with poor health outcomes among patients with chronic obstructive pulmonary disease (COPD) (1-4), which is a major cause of disability and mortality worldwide. While pulmonary rehabilitation that includes supervised exercise training is efficacious (5), several factors limit the reach of this intervention (6). Moreover, pulmonary rehabilitation and exercise training have not been consistently associated with an increase in daily levels of physical activity $(2-4,7)$, and there are very few trials of interventions to increase physical activity among patients with COPD compared with interventions of supervised exercise training (8-12).

Higher levels of physical activity are associated with better health, and there is strong evidence for the effectiveness of interventions to increase physical activity in the general population, among the elderly, and for patients with chronic diseases (13-15). However, there is inconsistent evidence for specific interventions to increase physical activity that improve health among patients with $\operatorname{COPD}(3,4)$.

To address this gap, we conducted a pragmatic, single-site, parallel-group randomized trial of COPD self-management education combined with a lifestyle behavioral intervention intended to increase daily physical activity as an alternative to pulmonary rehabilitation in a real-world sample of outpatients with COPD $(16,17)$. Our hypothesis was that patients who received the behavioral intervention would have significant improvements in healthrelated quality of life and functional performance compared with patients who receive usual care. Some of the results of this study were previously reported in the form of an abstract (18).

\section{Methods}

Detailed descriptions of patient recruitment (17) and the intervention (16) have been published previously. In brief, this study was a pragmatic randomized controlled trial comparing COPD self-management education plus a behavioral intervention for lifestyle physical activity with COPD selfmanagement education and usual care. A representative sample of patients was proactively recruited using a registry of patients with COPD cared for in primary and specialty care clinics of the University of Texas Health Science Center-Tyler (UTHSCT). The study was approved by the UTHSCT Institutional Review Board, and written informed consent was obtained before patient enrollment and data collection.

\section{Patient Recruitment}

The goal of recruitment was to enroll a broadly representative sample of patients with COPD eligible for but not participating in pulmonary rehabilitation. Patients at least 45 years of age with physician-diagnosed COPD were recruited from a registry $(\mathrm{n}=5,582)$ developed from an administrative database and provider referrals (17). The administrative database included all patients seen at the clinics with a coded COPD diagnosis (International Classification of Diseases, Ninth Revision, codes 491, 492, and 496). Determination of patient eligibility was conducted through multiple steps, including review of the medical records, telephone screening, and an enrollment visit to administer questionnaires and conduct spirometry and a 6-minute walk test. Briefly, patients were excluded if they had uncontrolled medical conditions, had participated in a pulmonary rehabilitation program within 12 months, or were nursing home residents (16).

\section{Run-in Period, Randomization, and Blinding}

During the first 6 weeks after enrollment, all patients were provided with COPD selfmanagement education delivered by manual and health coach. After this run-in period, patients were randomized using a permuted block design to usual care or the intervention. Group assignment was provided only to the study coordinator at enrollment. Group assignment was revealed to the health coach after the 6-week run-in period, but study personnel involved in follow-up data collection were blinded to group assignment. Patients randomized to usual care were directed by the health coach to continue regular follow-up with their physician and to call with any questions using a toll-free number.

\section{Physical Activity Intervention}

The intervention was adapted from an efficacious intervention for healthy sedentary persons $(16,19,20)$ and described in detail by Ashmore and coworkers (16).
Theoretical foundations for the intervention included social cognitive theory (21) and the transtheoretical model (22). The ultimate goal was to have patients accumulate at least 30 minutes of moderate-intensity physical activity per day (i.e., dyspnea level of 4-5 on the Borg scale and taking 1-2 minutes to recover). Briefly, the program was delivered through workbooks, telephone support from a health coach, and automated telephone calls. The foundation of the intervention was a 5 -workbook set totaling 25 chapters. Chapters 1-20 were completed weekly and focused on patient engagement in physical activity with a gradual increase to the goal. During this 20-week period, patients were contacted by the health coach every other week, which was supplemented with supportive messages from her delivered by automated calls in alternating weeks. The health coach tailored her interaction with each patient by focusing on the patient's understanding of key concepts, self-efficacy, readiness to change, problem solving, goal setting, adherence, and identification of barriers. Maintenance of physical activity objectives, covered in chapters $21-25$, was completed every other month thereafter.

\section{Health Coach Training and Monitoring Intervention Fidelity}

A single health coach was trained by the principal investigator in COPD selfmanagement education and by the health psychologist in health behavior change theory and practical counseling skills, including rapport building, active listening, and problem solving. To assess the quality of protocol adherence, a $10 \%$ random sample of audiotaped telephone counseling calls was evaluated by the health psychologist, using a standardized rating scale (see online supplement). Moreover, the dose of the intervention was examined using the total number of calls, mean number of calls per patient, and mean duration of calls for both groups during both the run-in and intervention phases (see online supplement).

\section{Data Collection}

At approximately 6, 12, and 18 months after enrollment, follow-up data were collected at UTHSCT. A detailed description of the data collection methods and instruments has been described previously (16). 


\section{Co-Primary Outcomes}

The two primary outcome measures included change from baseline to 18 months for the dyspnea domain of the selfadministered Chronic Respiratory Questionnaire (CRQ-SA) (23) and the 6-minute-walk distance (6MWD) (24). The CRQ-SA is a disease-specific instrument with 20 items and 4 domains (dyspnea, fatigue, emotional function, and mastery). Lower scores on the CRQ suggest worse health. For changes from baseline (baseline score subtracted from month 18), a negative difference suggests a worsening of CRQ, whereas a positive difference suggests an improvement in CRQ. The CRQ is responsive to change among patients with COPD, and the minimal clinically significant difference for each CRQ domain is $0.5(23,25)$.

A single 6-minute-walk test was administered by trained respiratory therapists according to the American Thoracic Society standardized protocol (24). Average differences between baseline and follow-up walk distance were used to determine treatment effect. The minimal clinically significant difference for the 6-minute walk ranges from 25 meters (26) to 35 meters (27).

\section{Process Outcomes}

To aid in the evaluation of the intervention, three process measures associated with physical activity were collected using standardized questionnaires and as described in detail previously (16). These measures included self-efficacy (28), readiness to change physical activity (19, 20, 29), and self-reported physical activity (30).

\section{Safety Monitoring}

Adverse events were identified using self-reports and hospitalization records at UTHSCT. These data were reviewed by the principal investigator, and all adverse events were reported to the institutional review board and data and safety monitoring board.

\section{Data Analysis}

Details of sample size estimation and statistical methods have been previously described (16). Briefly, a sample size of 129 subjects per group was estimated to achieve 95\% power at the 0.05 significance level, based on a minimal clinically significant difference of 0.5 for the CRQ dyspnea
(CRQ-D) domain (16). Moreover, an overall attrition rate of approximately $20 \%$ over the 18-month follow-up period was used to estimate the total number of patients needed to recruit. All outcome data were analyzed in the patient's original group assignment, regardless of their adherence to the intervention.

\section{Statistical Methods Used to Compare Groups}

Data are presented as mean and SD or frequency and percent for continuous and categorical variables, respectively. Ordinal variables with multiple categories and sparse data were categorized as follows: (1) readiness to change physical activity, categorized as high, intermediate, and low; and (2) self-reported physical activity, categorized as active, underactive, and sedentary. On the basis of self-report of 22 comorbid conditions, we calculated each subject's Charlson comorbidity index (17).

Between-group comparisons were made overall and were stratified by severity of spirometric impairment using independent samples $t$ tests and Fisher's exact test for continuous and categorical variables. In within-group analysis, we used a paired samples $t$ test. For co-primary and process outcomes, repeated measures analysis of variance (ANOVA) models were used to compare mean differences between the intervention and usual care groups over time.

The repeated measures model for longitudinal data analysis optimized all of the data available at each time point; that is, if a subject dropped out at month 12, then the model incorporated data available for the baseline and 6-month time points. Regardless of attrition and missing data, patients were assigned to the group to which they were randomized. The variables of interest in the models included: treatment group, time, and a treatment by time interactions. Statistical significance of the interaction term is of primary interest and determines whether or not the group means were changing at different rates for the outcomes.

We also controlled for the presence of the following potential confounders: age, sex, Global Initiative for Chronic Obstructive Lung Disease (GOLD) stage, readiness to change physical activity, and Charlson comorbidity index. We did not observe multicollinearity of predictors using the variance inflation factor cutoff of five.
Baseline comparisons of dropouts were made between (1) patients who dropped out during the run-in phase and enrolled patients, (2) usual care patients who dropped out during the intervention and usual care patients who completed the intervention, and (3) intervention patients who dropped out during the intervention and those who completed the intervention.

\section{Analysis of Adverse Events}

Adverse events were reported for both groups and categorized on the basis of type of event. Six categories of adverse events were identified: (1) death, (2) hospitalization-COPD exacerbation, (3) hospitalization-cardiac related, (4) hospitalization-other, (5) injury/fall, and (6) surgery. For the usual care and intervention groups, the total number of adverse events that occurred, the number of subjects with at least one adverse event, and the number of subjects who did not report any adverse events were recorded. Between-group differences in adverse event reporting were analyzed using Fisher's exact test.

\section{Results}

\section{Participant Flow and Baseline Characteristics}

A total of 325 patients were enrolled from April 2010 through September 2012; of these, 305 (93.8\%) completed the COPD self-management education and were randomized to the intervention or usual care group (Figure 1). Of these 305 patients, 247 $(81.0 \%)$ completed the study approximately 18 months after randomization. Overall, 78 (24.0\%) patients dropped out during the course of the trial, 20 during the selfmanagement education (17) and 58 after initiation of the physical activity intervention (see Table E1 in the online supplement).

Of the 305 patients who completed the self-management education, 149 (48.9\%) were randomized to the intervention group and $156(51.1 \%)$ to usual care (Figure 1). There were no clinically significant differences in demographic or health status indicators at baseline between the groups of randomized patients (Table 1) (17). At the third follow-up visit approximately 18 months after randomization, data were obtained for $113(75.8 \%)$ in the intervention group and $134(85.9 \%)$ in the 


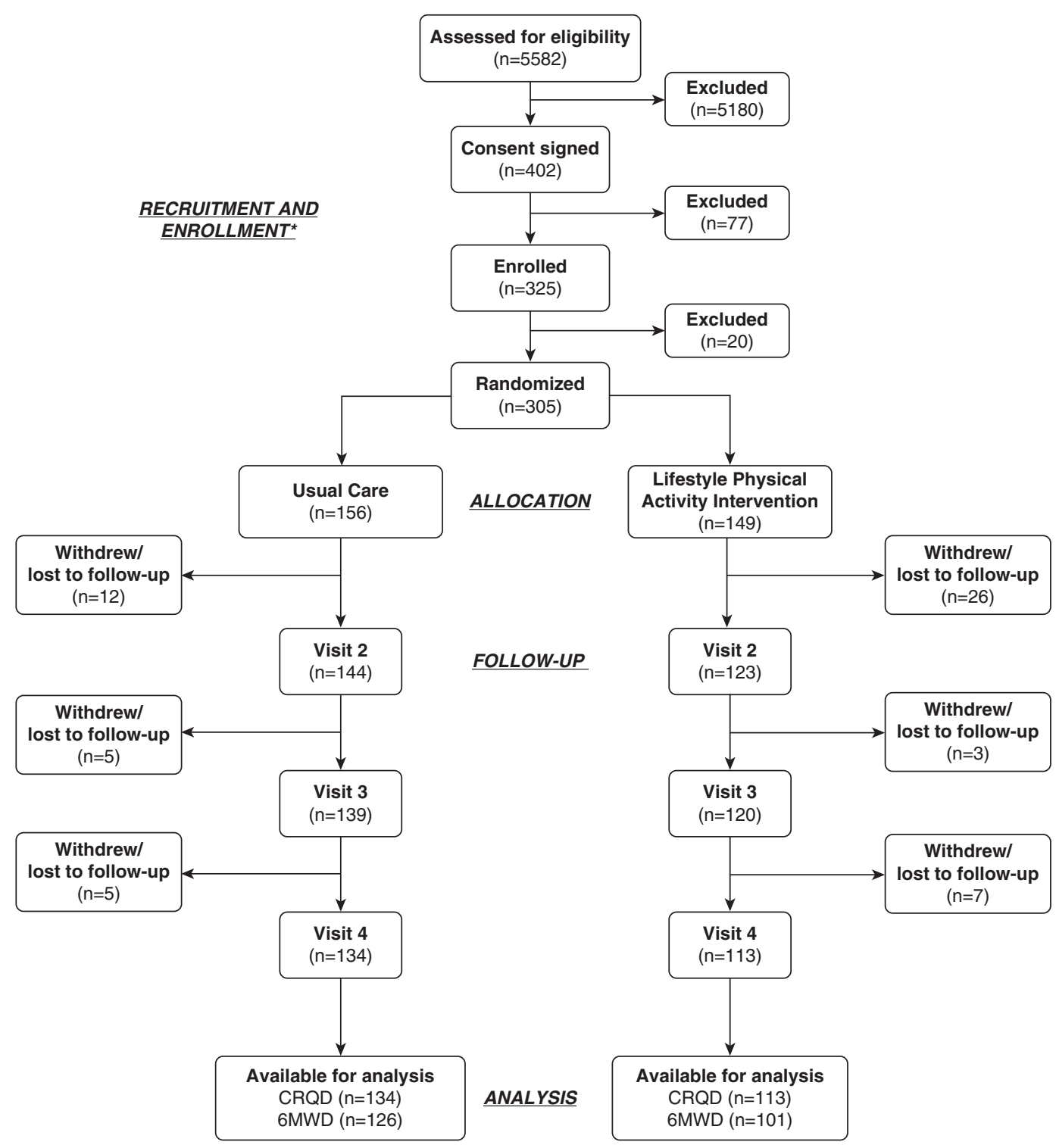

Figure 1. Study flow diagram of a randomized trial of a lifestyle physical activity intervention among patients with chronic obstructive pulmonary disease.

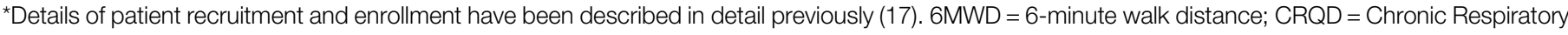
Questionnaire dyspnea domain.

usual care group. Moreover, the completion of data collection at 18 months varied by group and outcome. The highest completion rate was among the usual care group for CRQ-D (85.9\%); the rate was less for the intervention group $(75.8 \%)$. The $6 \mathrm{MWD}$ completion rates were lower for both groups, at $80.8 \%$ and $67.8 \%$, respectively.

\section{Measures of Physical Activity}

At baseline, there were no differences between the intervention and usual care groups in level of self-reported physical activity (Rapid Assessment of Physical Activity) (30), readiness to change physical activity $(19,20,29)$, or self-efficacy in managing and coping with dyspnea with physical activity (COPD Self-Efficacy Scale) (28) (Table 1). Overall, 56.58\% characterized their baseline level of physical activity as active, $27.96 \%$ as underactive, and $15.46 \%$ as sedentary. Baseline self-reported physical activity measured using the Rapid Assessment of Physical Activity was significantly correlated with baseline 6MWD $(\rho=0.18 ; P<0.0001)$. The majority reported their readiness to change physical activity as high (66.56\%), with $24.92 \%$ reporting it as intermediate and $8.52 \%$ as low. Among the self-efficacy domains, the least confidence (i.e., highest average score, 3) was reported for managing and coping with dyspnea during physical activity. See Table E2 for greater detail on changes of these surrogate measures of physical activity over the course of the trial.

\section{Results of Intervention on Co-Primary Outcomes}

Overall, for the co-primary outcomes of CRQ-D and 6MWD at 18 months, there 
Table 1. Baseline characteristics of patients randomized to usual care and behavioral intervention

\begin{tabular}{|c|c|c|c|}
\hline Variables & Total $(n=305)$ & UC $(n=156)$ & BI $(n=149)$ \\
\hline Age, yr, mean (SD) & $70.29(9.48)$ & $69.80(9.47)$ & $70.80(9.50)$ \\
\hline Female sex, $n(\%)$ & $154(50.49)$ & $79(50.64)$ & $75(50.34)$ \\
\hline \multicolumn{4}{|l|}{ Race/ethnicity, n (\%) } \\
\hline Hispanic & $4(1.31)$ & $2(1.28)$ & $2(1.34)$ \\
\hline $\mathrm{NH}$ white & $282(92.46)$ & $140(89.74)$ & $142(95.30)$ \\
\hline $\mathrm{NH}$ black & $18(5.9)$ & $13(8.33)$ & $5(3.36)$ \\
\hline $\mathrm{NH}$ other & $1(0.33)$ & $1(0.64)$ & $0(0)$ \\
\hline Rural $^{*}$ & 150 (49.34) & 81 (51.92) & $69(46.62)$ \\
\hline \multicolumn{4}{|l|}{ Smoking status, n (\%) } \\
\hline Current smoker & 76 (24.92) & $46(29.49)$ & $30(20.13)$ \\
\hline Ex-smoker & $206(67.54)$ & 99 (63.46) & $107(71.81)$ \\
\hline Never smoker & $23(7.54)$ & $11(7.05)$ & $12(8.05)$ \\
\hline Pack-years, mean (SD) & $58.22(36.76)$ & $57.05(34.32)$ & $59.47(39.27)$ \\
\hline \multicolumn{4}{|l|}{ GOLD stage, $\mathrm{n}(\%)$} \\
\hline II & 134 (43.93) & 75 (48.08) & $59(39.60)$ \\
\hline III & $130(42.62)$ & 59 (37.82) & $71(47.65)$ \\
\hline IV & $41(13.44)$ & $22(14.1)$ & $19(12.75)$ \\
\hline Charlson comorbidity index, m & $2.99(1.95)$ & $2.87(1.73)$ & $3.12(2.16)$ \\
\hline \multicolumn{4}{|l|}{ Comorbid conditions, $^{\dagger} \mathrm{n}(\%)$} \\
\hline \multicolumn{4}{|l|}{ Cardiovascular disorders } \\
\hline Hypertension & 174 (57.05) & $92(58.97)$ & $82(55.03)$ \\
\hline Congestive heart failure & 45 (14.75) & $21(13.46)$ & $24(16.11)$ \\
\hline Myocardial infarction & 39 (12.79) & $20(12.82)$ & 19 (12.75) \\
\hline Peripheral vascular disease & $20(6.56)$ & $6(3.85)$ & $14(9.4)$ \\
\hline Depression & $105(34.43)$ & 50 (32.05) & $55(36.91)$ \\
\hline Diabetes & $62(20.33)$ & 25 (16.03) & $37(24.83)$ \\
\hline Ulcer disease & $24(7.87)$ & $14(8.97)$ & $10(6.71)$ \\
\hline \multicolumn{4}{|l|}{ Rapid Assessment of Physical Activity, $\mathrm{n}(\%)$} \\
\hline Sedentary & $47(1$ & $.74)$ & $6.22)$ \\
\hline Underactive & $85(27.96)$ & $45(28.85)$ & $40(27.03)$ \\
\hline Active & $172(56.58)$ & $88(56.41)$ & $84(56.76)$ \\
\hline \multicolumn{4}{|l|}{ Readiness to change physical activity, $\mathrm{n}(\%)$} \\
\hline High & $203(66.56)$ & 107 (68.59) & $96(64.43)$ \\
\hline Intermediate & $76(24.92)$ & $38(24.37)$ & $38(25.50)$ \\
\hline Low & $26(8.52)$ & $11(7.05)$ & $15(10.07)$ \\
\hline \multicolumn{4}{|l|}{ COPD Self-Efficacy Scale, mean (SD) } \\
\hline Negative affect & $2.53(0.88)$ & $2.54(0.90)$ & $2.52(0.86)$ \\
\hline Emotional arousal & $2.38(0.79)$ & $2.40(0.81)$ & $2.36(0.77)$ \\
\hline Physical exertion & $3.00(0.92)$ & $3.03(0.89)$ & $2.97(0.94)$ \\
\hline Weather/environment & $2.77(0.83)$ & $2.74(0.83)$ & $2.79(0.84)$ \\
\hline Behavior & $2.67(0.89)$ & $2.62(0.91)$ & $2.72(0.87)$ \\
\hline
\end{tabular}

Definition of abbreviations: $\mathrm{BI}$ = behavioral intervention; COPD = chronic obstructive pulmonary disease; GOLD = Global Initiative for Obstructive Lung Disease; $\mathrm{NH}=$ non-Hispanic; $U \mathrm{C}=$ usual care. ${ }^{*}$ Rural residence based on Urban Influence Codes.

${ }^{\dagger}$ Comorbid conditions with prevalence greater than $5 \%$.

were no statistical or clinically significant differences between the usual care and intervention groups (Table 2). Moreover, there was little absolute change for CRQ-D at 18 months compared with baseline for either the usual care group $(-0.09$ $[P=0.43])$ or the intervention group $(-0.03[P=0.82])$, with no difference between groups $(P=0.71)$. When stratified by severity of lung function impairment, there was no change in CRQ-D at 18 months for GOLD stages II and III. However, for GOLD stage IV, both groups had clinically significant declines in
CRQ-D $(-0.55[P=0.04]$ for usual care; $-0.79[P=0.19]$ for intervention) at 18 months (Figure 2). Over the course of the 18 months, average CRQ-D scores varied between the intervention and usual care groups and by severity of lung function impairment (Figure 2) $(P=0.05$ for ANOVA interaction term). Among the intervention group, there were clinically significant improvements in CRQ-D compared with usual care at 6 months that declined at 12 and 18 months. The improvement in CRQ-D at 6 months was limited to GOLD stage II.
Among both groups, there were statistically but not clinically significant declines in 6MWD over the 18 months. The average declines were -22.6 meters for the usual care group $(P<0.001)$ and -13.6 meters for the intervention group $(P<0.001)$, but there was no statistical difference between the groups $(P=0.31)$. When stratified by severity of lung function impairment, all groups had declines in 6MWD over the 18 months, except for the intervention group in GOLD stage II (+5.34 m), which, when compared with the usual care group in GOLD stage II $(-28.68$ $\mathrm{m})$, was significantly different both statistically $(P<0.003)$ and clinically $(-34.02 \mathrm{~m})$ (Table 2, Figure 3$)$. This difference $(-34.02 \mathrm{~m})$ was within the 25 meters (26) to 35 meters (27) range for minimal clinically significant difference (Table 2, Figure 3).The repeated-measures ANOVA interaction term further supports these results $(P=0.007)$.

\section{Adverse Events}

A total of 194 adverse events were reported during the 18-month course of the study, with no differences between the groups $(P=0.80)$ (Table 3$)$. Of the 305 patients randomized, $63 \%$ had no adverse events and $37 \%$ had at least one adverse event. While hospitalizations for exacerbations of COPD were the most common adverse event in both groups, they occurred nearly twice as frequently among those in the usual care group compared with the intervention group (49.47\% vs. $28.28 \%$; $P<0.01)$. In contrast, the intervention group had more hospitalizations for other medical conditions and surgeries $(42.42 \%)$ than the usual care group $(26.32 \%)(P=0.02)$. While the percentage of patients reporting serious adverse events was higher in the usual care group than in the behavioral intervention group, the differences were not statistically different (usual care, $75.79 \%$; behavioral intervention, $66.66 \%$; $P=0.21)$.

\section{Discussion}

Overall, during this 18-month behavioral intervention to increase lifestyle physical activity among a representative sample of outpatients with COPD (17), there was no improvement in health-related quality of life or functional performance. 
Table 2. Primary outcomes at baseline, month 18, and change from baseline

\begin{tabular}{|c|c|c|c|c|c|c|c|c|c|c|c|c|c|}
\hline & & \multicolumn{4}{|c|}{ Baseline } & \multicolumn{4}{|c|}{ Month 18} & \multicolumn{4}{|c|}{ Change from Baseline } \\
\hline & & \multicolumn{2}{|c|}{ UC $(n=156)$} & \multicolumn{2}{|c|}{ BI $(n=149)$} & \multicolumn{2}{|c|}{ UC $(n=134)$} & \multicolumn{2}{|c|}{$\mathrm{BI}(n=113)$} & \multirow[b]{2}{*}{ UC } & \multirow[b]{2}{*}{ BI } & \multirow[b]{2}{*}{$\begin{array}{c}\text { Between- } \\
\text { Group } \\
P \text { Value }\end{array}$} & \multirow[b]{2}{*}{$\begin{array}{c}\text { Interaction } \\
\text { Term } \\
P \text { Value* }\end{array}$} \\
\hline & & Mean & SD & Mean & SD & Mean & SD & Mean & SD & & & & \\
\hline $\begin{array}{l}\text { Overall } \\
\qquad(n=305)\end{array}$ & $\begin{array}{l}\text { CRQ-D } \\
6 M W D\end{array}$ & $\begin{array}{r}4.33 \\
337.50\end{array}$ & $\begin{array}{r}1.35 \\
96.37\end{array}$ & $\begin{array}{r}4.48 \\
342.80\end{array}$ & $\begin{array}{r}1.30 \\
91.03\end{array}$ & $\begin{array}{r}4.23 \\
324.10\end{array}$ & $\begin{array}{r}1.49 \\
107.50\end{array}$ & $\begin{array}{r}4.50 \\
343.10\end{array}$ & $\begin{array}{r}1.39 \\
99.81\end{array}$ & $\begin{array}{r}-0.09 \\
-22.6^{\dagger}\end{array}$ & $\begin{array}{r}-0.03 \\
-13.6^{\dagger}\end{array}$ & $\begin{array}{l}0.714 \\
0.309\end{array}$ & $\begin{array}{l}0.176 \\
0.284\end{array}$ \\
\hline $\begin{array}{l}\text { Stage } 2 \\
\quad(n=134)\end{array}$ & $\begin{array}{l}\text { CRQ-D } \\
\text { 6MWD }\end{array}$ & $\begin{array}{r}4.60 \\
360.80\end{array}$ & $\begin{array}{r}1.39 \\
91.57\end{array}$ & $\begin{array}{r}4.76 \\
368.90\end{array}$ & $\begin{array}{r}1.21 \\
84.89\end{array}$ & $\begin{array}{r}4.57 \\
336.00\end{array}$ & $\begin{array}{r}1.53 \\
104.40\end{array}$ & $\begin{array}{r}4.86 \\
380.70\end{array}$ & $\begin{array}{r}1.26 \\
90.11\end{array}$ & $\begin{array}{c}-0.07 \\
-28.68^{\dagger}\end{array}$ & $\begin{array}{l}0.08 \\
5.34\end{array}$ & $\begin{array}{l}0.552 \\
0.003\end{array}$ & $\begin{array}{l}0.381 \\
0.006\end{array}$ \\
\hline $\begin{array}{l}\text { Stage } 3 \\
\quad(n=130)\end{array}$ & $\begin{array}{l}\text { CRQ-D } \\
\text { 6MWD }\end{array}$ & $\begin{array}{r}4.19 \\
321.80\end{array}$ & $\begin{array}{r}1.37 \\
97.71\end{array}$ & $\begin{array}{r}4.40 \\
338.00\end{array}$ & $\begin{array}{r}1.37 \\
87.77\end{array}$ & $\begin{array}{r}4.17 \\
327.90\end{array}$ & $\begin{array}{r}1.37 \\
112.30\end{array}$ & $\begin{array}{r}4.43 \\
314.30\end{array}$ & $\begin{array}{r}1.35 \\
98.81\end{array}$ & $\begin{array}{r}0.06 \\
-9.96\end{array}$ & $\begin{array}{c}0.00 \\
-34.17^{\dagger}\end{array}$ & $\begin{array}{l}0.844 \\
0.089\end{array}$ & 0.660 \\
\hline $\begin{array}{l}\text { Stage } 4 \\
\qquad(n=41)\end{array}$ & $\begin{array}{l}\text { CRQ-D } \\
\text { 6MWD }\end{array}$ & $\begin{array}{r}3.78 \\
299.90\end{array}$ & $\begin{array}{r}0.96 \\
92.33\end{array}$ & $\begin{array}{r}3.91 \\
279.30\end{array}$ & $\begin{array}{r}1.10 \\
91.52\end{array}$ & $\begin{array}{r}3.25 \\
275.00\end{array}$ & $\begin{array}{r}1.19 \\
98.29\end{array}$ & $\begin{array}{r}2.96 \\
291.10\end{array}$ & $\begin{array}{r}1.27 \\
90.14\end{array}$ & $\begin{array}{r}-0.55^{\dagger} \\
-29.66\end{array}$ & $\begin{array}{l}-0.79 \\
-9.49\end{array}$ & $\begin{array}{l}0.655 \\
0.573\end{array}$ & $\begin{array}{l}0.178 \\
0.052 \\
0.516\end{array}$ \\
\hline
\end{tabular}

Definition of abbreviations: $6 \mathrm{MWD}=6$-minute-walk distance; $\mathrm{BI}$ = behavioral intervention; $\mathrm{CRQ}-\mathrm{D}=$ Chronic Respiratory Questionnaire dyspnea domain; GOLD = Global Initiative for Chronic Obstructive Lung Disease; UC = usual care.

${ }^{*}$ Repeated-measures analysis of variance model: Outcome $=$ Group + Time + Group $\times$ Time + Age + Sex + GOLD stage + Charlson comorbidity index + Baseline readiness to change physical activity score. Interaction term $P$ value was based on the repeated-measures analysis of variance group $\times$ time interaction term. Interaction can be interpreted as between-group differences in the relationship between time and outcome.

${ }^{+}$Statistically significant difference from baseline values at the $\alpha=0.05$ level.

However, subgroup analyses suggested that response to the intervention varied by type of outcome measure and severity of spirometric impairment.
In a self-management trial reported by Mitchell and coworkers (31), the authors found little overall change in CRQ-D, which was similar to our findings.
However, in our trial, patients in both groups with very severe impairment had clinically significant declines in CRQ-D. Similarly, clinically significant declines in
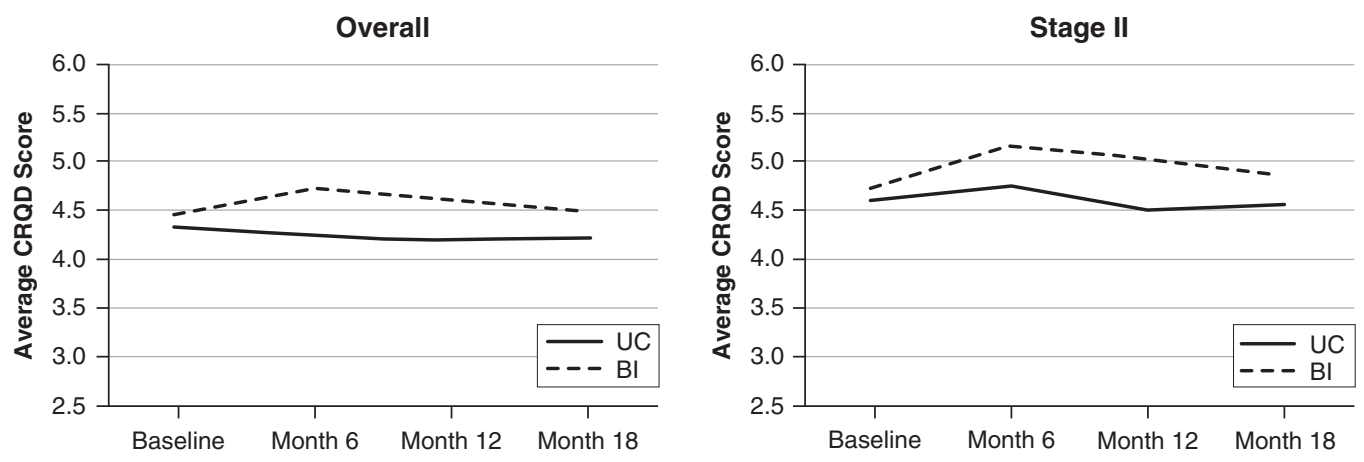

Stage III
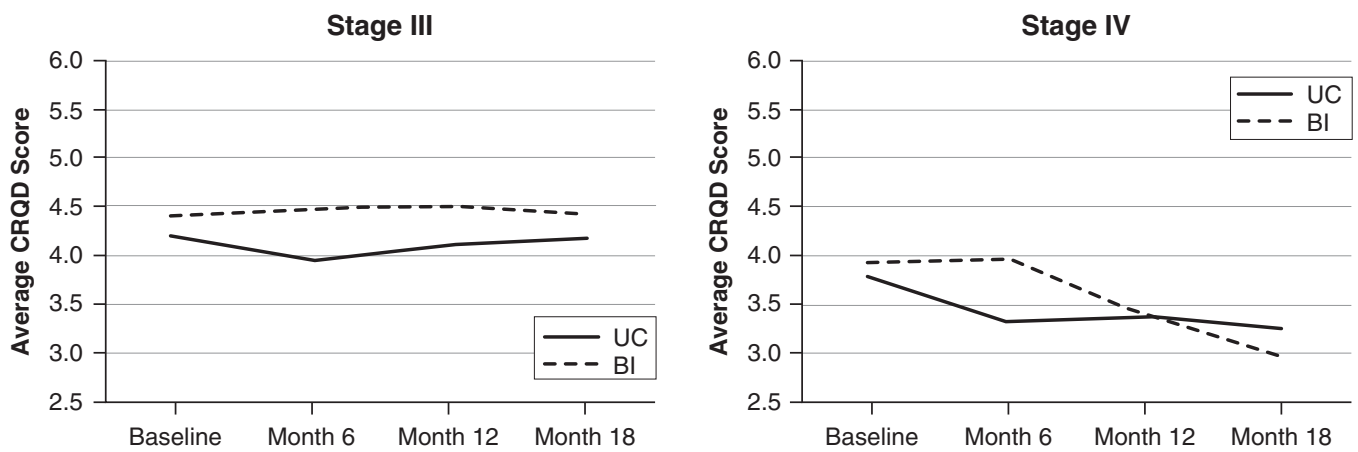

Figure 2. Average Chronic Respiratory Questionnaire dyspnea domain (CRQD) scores over the 18-month study period for overall sample and stratified by Global Initiative for Chronic Obstructive Lung Disease stage. $\mathrm{BI}=$ behavioral intervention; UC = usual care. 

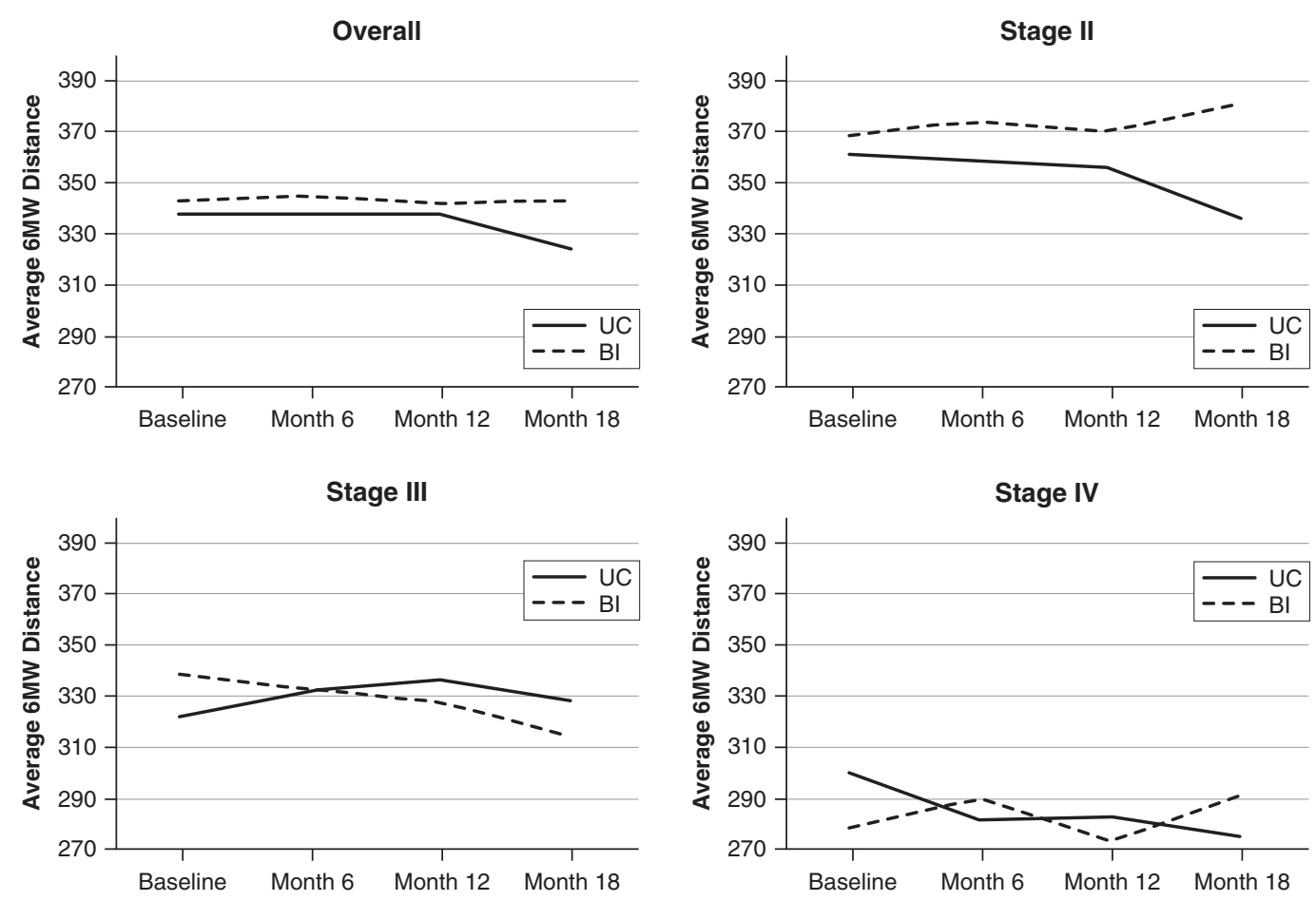

Figure 3. Average 6-minute-walk (6MW) distance over the 18-month study period for overall sample and stratified by Global Initiative for Chronic Obstructive Lung Disease stage. $\mathrm{BI}=$ behavioral intervention; $\mathrm{UC}=$ usual care.

6MWD were found among all patients, except for those with moderate spirometric impairment who received the intervention. These results are consistent with findings derived from an observational cohort study of 398 patients with COPD followed for 3 years in whom decline in 6MWD was associated with greater severity of spirometric impairment and lower levels of self-reported physical activity (32). Moreover, longitudinal decline in physical activity has been objectively documented among patients with COPD and is associated with impairment of 6MWD (33). Overall, in our study, there was no difference in adverse events between the two groups; however, there was a significantly lower prevalence of self-reported hospitalizations for COPD exacerbations in the intervention group.

This trial has a number of strengths, which include design elements recommended for behavioral interventions to increase physical activity among patients with COPD (34). Moreover, this trial addresses many of the limitations of previous trials conducted in this population (3). Chief among these strengths are the randomized controlled design with sufficient statistical power for the coprimary outcomes, a representative sample of patients from primary and specialty care (17), a theory- and evidence-based behavioral intervention (16), a lifestyle approach to increasing physical activity versus structured exercise, and an 18-month follow-up to permit sufficient time for adoption and maintenance of the lifestyle change.

Our results suggest that patient-, methodology-, intervention-, and outcome-related factors may have influenced the results. While there was no overall benefit of the intervention at 18 months, the intervention was associated with prevention of decline in $6 \mathrm{MWD}$ among patients with moderate spirometric impairment. This may be due to the promotion of higher levels of physical activity associated with the intervention among patients with moderate impairment as a result of greater confidence (e.g., less fear of dyspnea) and more motivation to engage in physical activity than possessed by patients with greater severity of spirometric impairment (data not shown). Another factor that may have influenced the results was differential dropout rates, with a higher prevalence of missing $6 \mathrm{MWD}$ data in the intervention group (32.2\%) than in the usual care group (19.2\%). However, the higher dropout rate in the intervention group was limited to patients with more severe spirometric impairment (Table E1), which cannot explain our overall negative findings and would not have affected the results for patients with moderate impairment.

At baseline, a majority of patients in both groups reported being active, which may have limited the opportunity for improvement with the intervention. However, individual patients likely overestimate their average self-reported levels of physical activity $(35,36)$. These findings suggest that an opportunity likely remained to increase level of physical activity among a potentially large proportion of patients who may have overestimated their self-reported level of activity.

Methodological and interventionrelated factors may have contributed to the lack of overall effectiveness. These factors include delivery of self-management education to the control group and insufficient fidelity, gaps, and/or limited adherence to the intervention. While both control and intervention groups received 
Table 3. Adverse events among all randomized subjects

\begin{tabular}{|c|c|c|c|c|c|}
\hline \multirow{2}{*}{$\begin{array}{l}\text { Characteristics } \\
\text { Adverse events }\end{array}$} & \multicolumn{2}{|c|}{ UC $(n=156[\%])$} & \multicolumn{2}{|c|}{ BI $(n=149[\%])$} & \multirow[t]{2}{*}{$P$ Value* } \\
\hline & 95 & $(48.97)$ & 99 & $(51.03)$ & \\
\hline \multicolumn{6}{|l|}{ Total adverse events } \\
\hline Subjects with $\geqslant 1 \mathrm{AE}$ & 65 & $(41.67)$ & 60 & $(40.27)$ & 0.80 \\
\hline Subjects with no AEs & 91 & (58.33) & 89 & (59.73) & \\
\hline \multicolumn{6}{|l|}{ Postrandomization adverse events } \\
\hline Subjects with $\geqslant 1 \mathrm{AE}$ & 59 & $(37.82)$ & 53 & $(35.57)$ & 0.94 \\
\hline Subjects with no AEs & 97 & $(62.18)$ & 96 & $(64.43)$ & \\
\hline \multicolumn{6}{|l|}{ Prerandomization adverse events } \\
\hline Subjects with $\geqslant 1 \mathrm{AE}$ & 6 & $(3.85)$ & 7 & $(4.69)$ & 0.71 \\
\hline Subjects with no AEs & 150 & $(96.15)$ & 142 & (95.31) & \\
\hline \multicolumn{6}{|l|}{ Adverse event categories } \\
\hline Death & 4 & $(4.21)$ & 4 & $(4.04)$ & \\
\hline Hospitalization-cardiac & 10 & $(10.53)$ & 13 & $(13.13)$ & \\
\hline Hospitalization-exacerbation & 47 & $(49.47)$ & 28 & $(28.28)$ & \\
\hline Hospitalization-other & 11 & (11.58) & 21 & $(21.21)$ & \\
\hline Injury/fall & 9 & $(9.47)$ & 12 & (12.12) & \\
\hline Surgery ${ }^{\dagger}$ & 14 & $(14.74)$ & 21 & $(21.21)$ & \\
\hline Subjects with SAEs & 72 & $(75.79)$ & 66 & (66.66) & 0.20 \\
\hline
\end{tabular}

Definition of abbreviations: $\mathrm{AE}=$ adverse event; $\mathrm{BI}=$ behavioral intervention; $\mathrm{SAE}=$ serious adverse event; UC = usual care.

${ }^{\star} P$ values correspond to $\chi^{2}$ test.

†'Surgeries were non-COPD related.

self-management education without a behavior change component, education alone was unlikely to increase physical activity and to explain the lack of effectiveness (13). Overall, the fidelity of the intervention was judged to be satisfactory on the basis of our assessment of overall quality and frequency and/or duration of the health coach calls (Table E3). Moreover, overall improvement of surrogate measures of physical activity (Table E2) among the intervention group provides further evidence that the intervention was delivered as intended.

There are a number of components of the intervention that may have been insufficient and may have weakened the effect on physical activity, including inadequate dose of the intervention and training effect (i.e., intensity, duration, frequency), insufficient tailoring to patient needs (e.g., severity of spirometric impairment, intercurrent illness, selfefficacy, motivation), and lack of engagement by the patient's physician. Factors that may have affected the dose of the intervention included the time for which the patient was engaged using the manual and/or frequency and duration of health coach calls. Of these factors, data are available only for frequency and duration of health coach calls, which together totaled approximately 2.2 hours for the intervention group and 0.9 hours for the control group (Table E3). This was slightly less than comparable interventions that relied primarily on individual counseling provided by Stulbarg and colleagues (37) and Hospes and colleagues (10) at 3.0 hours and 2.5 hours, respectively.

The goal of increasing physical activity is to reverse the deconditioning associated with physical inactivity, which requires a physiological training effect (2). For this intervention, the physical activity target was an accumulation of at least 30 minutes of moderate-level physical activity 5 days per week. Moderate level was selfassessed by the patient during physical activity as a dyspnea level of $4-5$ on the Borg scale and taking 1-2 minutes to recover. However, without objective measurement of the level of physical activity, including intensity, frequency, and duration, we cannot be certain whether there was sufficient adherence to this target or training effect.

While adherence to the intervention is frequently used as an exclusion criterion in studies of exercise training or physical activity (8), this is an unrealistic expectation because patients have exacerbations, surgeries, or personal problems that may interfere with their ability to consistently participate in physical activity, which likely attenuates treatment effects. In our sample, we found that at 6 months over $30 \%$ of patients were late for their data collection visit, which was often associated with COPD exacerbations, intercurrent illnesses, and surgeries (Tables E4 and E5).

Other factors that may have limited the effectiveness of the intervention include insufficient attention to patient-related factors or inadequate time for the intervention. While the randomized design controlled for confounders, the impact of the intervention may have been limited by uncontrolled symptoms, low self-efficacy and motivation (38), and comorbidities that were not adequately addressed with the intervention. For example, fear of dyspnea with exertion is a common barrier, and there may have been insufficient attention to this concern (2), particularly for patients with more severe impairment, who may require greater supervision to support selfefficacy (38-40). Moreover, a physician's advice and encouragement have a strong influence on participation in pulmonary rehabilitation programs (6), but the level of engagement and support of the intervention by physicians was uncertain. Similarly, social support is an important determinant of physical activity $(13,34)$, and other than their immediate social network there was no opportunity for peer support.

\section{Conclusions}

Our results suggest that a lifestyle physical activity intervention combined with selfmanagement education may be effective in maintaining functional performance over 18 months, but not health-related quality of life, among a representative sample of patients with moderate spirometric impairment. Moreover, while the intervention was not associated with an increase in adverse events, there was suggestive evidence for a lower prevalence of hospitalizations for COPD exacerbations.

Because our intervention provided minimal support, future studies are needed to test the effectiveness of providing greater engagement by physicians as well as greater peer support, and of ensuring that patients engage in higher levels of physical activity (e.g., intensity, frequency, duration) through greater supervision, particularly for patients with severe impairment. Moreover, because of the 
overall low engagement in and completion of the intervention, greater understanding of the psychological determinants of physical activity is needed to provide better support for patients with COPD at various levels of readiness to change physical activity. Finally, advances in technology with accelerometers and enhanced messaging may improve ability to provide a targeted physical activity prescription and behavioral support.

Author disclosures are available with the text of this article at www.atsjournals.org.
Acknowledgment: The authors gratefully acknowledge the study participants and research staff members Toyua Akers and Ginny Harleston, as well as the staff of UTHSCT Cardiopulmonary Services. Health Kinetics, publisher of Active Living Every Day, offered their support and permission to adapt their materials for this research.

\section{References}

1 Park SK, Richardson CR, Holleman RG, Larson JL. Physical activity in people with COPD, using the National Health and Nutrition Evaluation Survey dataset (2003-2006). Heart Lung 2013;42: 235-240.

2 Troosters T, van der Molen T, Polkey M, Rabinovich RA, Vogiatzis I, Weisman I, Kulich K. Improving physical activity in COPD: towards a new paradigm. Respir Res 2013;14:115.

3 Gimeno-Santos E, Frei A, Steurer-Stey C, de Batlle J, Rabinovich RA, Raste Y, Hopkinson NS, Polkey MI, van Remoortel H, Troosters T, et al.; PROactive consortium. Determinants and outcomes of physical activity in patients with COPD: a systematic review. Thorax 2014;69:731-739.

4 Watz H, Pitta F, Rochester CL, Garcia-Aymerich J, ZuWallack R, Troosters T, Vaes AW, Puhan MA, Jehn M, Polkey MI, et al. An official European Respiratory Society statement on physical activity in COPD. Eur Respir J 2014;44:1521-1537.

5 Spruit MA, Singh SJ, Garvey C, ZuWallack R, Nici L, Rochester C, Hill K, Holland AE, Lareau SC, Man WD, et al.; ATS/ERS Task Force on Pulmonary Rehabilitation. An official American Thoracic Society/ European Respiratory Society statement: key concepts and advances in pulmonary rehabilitation. Am J Respir Crit Care Med 2013;188:e13-e64.

6 Keating A, Lee A, Holland AE. What prevents people with chronic obstructive pulmonary disease from attending pulmonary rehabilitation? A systematic review. Chron Respir Dis 2011;8:89-99.

7 Pitta F, Troosters T, Probst VS, Langer D, Decramer M, Gosselink R. Are patients with COPD more active after pulmonary rehabilitation? Chest 2008;134:273-280.

8 Puente-Maestu L, Sánz ML, Sánz P, Cubillo JM, Mayol J, Casaburi R. Comparison of effects of supervised versus self-monitored training programmes in patients with chronic obstructive pulmonary disease. Eur Respir J 2000;15:517-525.

9 Liu WT, Wang CH, Lin HC, Lin SM, Lee KY, Lo YL, Hung SH, Chang YM, Chung KF, Kuo HP. Efficacy of a cell phone-based exercise programme for COPD. Eur Respir J 2008;32:651-659.

10 Hospes G, Bossenbroek L, Ten Hacken NHT, van Hengel P, de Greef MHG. Enhancement of daily physical activity increases physical fitness of outclinic COPD patients: results of an exercise counseling program. Patient Educ Couns 2009;75:274-278.

11 Donesky D, Janson SL, Nguyen HQ, Neuhaus J, Neilands TB, CarrieriKohlman V. Determinants of frequency, duration, and continuity of home walking in patients with COPD. Geriatr Nurs 2011;32:178-187.

12 Martinez CH, Moy ML, Nguyen $\mathrm{HQ}$, Cohen M, Kadri R, Roman P, Holleman RG, Kim HM, Goodrich DE, Giardino ND, et al. Taking Healthy Steps: rationale, design and baseline characteristics of a randomized trial of a pedometer-based Internet-mediated walking program in veterans with chronic obstructive pulmonary disease. BMC Pulm Med 2014;14:12.

13 Heath GW, Parra DC, Sarmiento OL, Andersen LB, Owen N, Goenka S, Montes F, Brownson RC; Lancet Physical Activity Series Working Group. Evidence-based intervention in physical activity: lessons from around the world. Lancet 2012;380:272-281.

14 Durstine JL, Gordon B, Wang Z, Luo X. Chronic disease and the link to physical activity. J Sport Health Sci 2013;2:3-11.

15 Pahor M, Guralnik JM, Ambrosius WT, Blair S, Bonds DE, Church TS, Espeland MA, Fielding RA, Gill TM, Groessl EJ, et al.; LIFE study investigators. Effect of structured physical activity on prevention of major mobility disability in older adults: the LIFE study randomized clinical trial. JAMA 2014;311:2387-2396.

16 Ashmore J, Russo R, Peoples J, Sloan J, Jackson BE, Bae S, Singh KP Blair SN, Coultas D. Chronic obstructive pulmonary disease selfmanagement activation research trial (COPD-SMART): design and methods. Contemp Clin Trials 2013;35:77-86.

17 Russo R, Coultas D, Ashmore J, Peoples J, Sloan J, Jackson BE, Uhm M, Singh KP, Blair SN, Bae S. Chronic obstructive pulmonary disease self-management activation research trial (COPD-SMART): results of recruitment and baseline patient characteristics. Contemp Clin Trials 2015;41:192-201.

18 Jackson BE, Coultas D, Russo R, Ashmore J, Sloan J, Uhm M, Singh $\mathrm{KP}$, Bae S. Benefits of a lifestyle physical activity intervention for COPD are limited to patients with moderate impairment [abstract]. Am J Respir Crit Care Med 2015;191:A4448.

19 Dunn AL, Marcus BH, Kampert JB, Garcia ME, Kohl HW III, Blair SN. Comparison of lifestyle and structured interventions to increase physical activity and cardiorespiratory fitness: a randomized trial. JAMA 1999;281:327-334.

20 Blair SN, Dunn AL, Marcus BH, Carpenter RA, Jaret P. Active living every day: get active with a proven step-by-step program, 2nd ed. Champaign, IL: Human Kinetics; 2011.

21 Bandura A. Health promotion by social cognitive means. Health Educ Behav 2004;31:143-164.

22 Prochaska JO, DiClemente CC. Stages and processes of self-change of smoking: toward an integrative model of change. J Consult Clin Psychol 1983;51:390-395.

23 Schünemann HJ, Griffith L, Jaeschke R, Goldstein R, Stubbing D, Austin $\mathrm{P}$, Guyatt $\mathrm{GH}$. A comparison of the original chronic respiratory questionnaire with a standardized version. Chest 2003;124: 1421-1429.

24 ATS Committee on Proficiency Standards for Clinical Pulmonary Function Laboratories. ATS statement: guidelines for the six-minute walk test. Am J Respir Crit Care Med 2002;166:111-117.

25 Jaeschke R, Singer J, Guyatt GH. Measurement of health status: ascertaining the minimal clinically important difference. Control Clin Trials 1989;10:407-415.

26 Holland AE, Hill CJ, Rasekaba T, Lee A, Naughton MT, McDonald CF. Updating the minimal important difference for six-minute walk distance in patients with chronic obstructive pulmonary disease. Arch Phys Med Rehabil 2010;91:221-225.

27 Puhan MA, Mador MJ, Held U, Goldstein R, Guyatt GH, Schünemann HJ. Interpretation of treatment changes in 6-minute walk distance in patients with COPD. Eur Respir J 2008;32:637-643.

28 Wigal JK, Creer TL, Kotses H. The COPD Self-Efficacy Scale. Chest 1991;99:1193-1196.

29 Marcus BH, Forsyth LH. Motivating people to be physically active. 2nd ed. Champaign, IL: Human Kinetics; 2009.

30 Topolski TD, LoGerfo J, Patrick DL, Williams B, Walwick J, Patrick MB. The Rapid Assessment of Physical Activity (RAPA) among older adults. Prev Chronic Dis 2006;3:A118.

31 Mitchell KE, Johnson-Warrington V, Apps LD, Bankart J, Sewell L, Williams JE, Rees K, Jolly K, Steiner M, Morgan M, Singh SJ. A self-management programme for COPD: a randomised controlled trial. Eur Respir J 2014;44:1538-1547.

32 Frisk B, Espehaug B, Hardie JA, Strand LI, Moe-Nilssen R, Eagan TM, Bakke PS, Thorsen E. Physical activity and longitudinal change in 6-min walk distance in COPD patients. Respir Med 2014;108:86-94.

33 Waschki B, Kirsten AM, Holz O, Mueller KC, Schaper M, Sack AL, Meyer T, Rabe KF, Magnussen H, Watz H. Disease progression and 
changes in physical activity in patients with chronic obstructive pulmonary disease. Am J Respir Crit Care Med 2015;192:295-306.

34 Leidy NK, Kimel M, Ajagbe L, Kim K, Hamilton A, Becker K. Designing trials of behavioral interventions to increase physical activity in patients with COPD: insights from the chronic disease literature. Respir Med 2014;108:472-481.

35 Pitta F, Troosters T, Spruit MA, Decramer M, Gosselink R. Activity monitoring for assessment of physical activities in daily life in patients with chronic obstructive pulmonary disease. Arch Phys Med Rehabil 2005;86:1979-1985.

36 Tucker JM, Welk GJ, Beyler NK. Physical activity in U.S.: adults compliance with the Physical Activity Guidelines for Americans. Am J Prev Med 2011;40:454-461.
37 Stulbarg MS, Carrieri-Kohlman V, Demir-Deviren S, Nguyen HQ, Adams L, Tsang AH, Duda J, Gold WM, Paul S. Exercise training improves outcomes of a dyspnea self-management program. $J$ Cardiopulm Rehabil 2002;22:109-121.

38 Williams V, Bruton A, Ellis-Hill C, McPherson K. The effect of pulmonary rehabilitation on perceptions of breathlessness and activity in COPD patients: a qualitative study. Prim Care Respir J 2010;19:45-51.

39 Danilack VA, Weston NA, Richardson CR, Mori DL, Moy ML. Reasons persons with COPD do not walk and relationship with daily step count. COPD 2014;11:290-299.

40 Wortz K, Cade A, Menard JR, Lurie S, Lykens K, Bae S, Jackson B, Su F, Singh K, Coultas D. A qualitative study of patients' goals and expectations for self-management of COPD. Prim Care Respir J 2012;21:384-391. 